\title{
Theoretical evaluation of Huber and Smalian methods applied to tree stem classical geometries
}

\author{
Evaluación teórica de los métodos de Huber y Smalian aplicados a las geometrías \\ clásicas de tronco de árbol
}

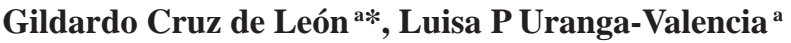 \\ *Corresponding author: a Universidad Michoacana de San Nicolás de Hidalgo, Facultad de Ingeniería en Tecnología de la Madera, \\ Apartado Postal 580, C.P. 58000, Morelia Michoacán, México, tel./fax: (443) 32603 79, gcruzl@umich.mx
}

\begin{abstract}
SUMMARY
Huber, Smalian and Newton methods, to estimate tree stem and log volume by sections, were theoretically evaluated applying them to the geometries of paraboloid, cone and neiloid. The study follows approximation procedures from calculus for volume estimation of solids of revolution as function of the number of segments and error analysis methods from forest measurement research. The errors in using Huber and Smalian methods have been determined. Additionally, it was algebraically proved that the Huber's error is exactly one half of the Smalian's error and opposite in sign. The results predict that, for any tree stem modeled classically, Huber's and Smalian's average absolute percent errors should be: less than $13.5 \%$ and $27 \%$, respectively, for five or more segments; less than $7 \%$ and $14 \%$, for 10 or more segments; less than $3.6 \%$ and $7.2 \%$, for 20 or more segments; less than $2.5 \%$ and $5 \%$, for 30 or more segments. This work provides a quantization on the classical theory of tree stem and log volume estimation. It could help to unify that theory and make it a more compact reference for forest measurement teaching and research.
\end{abstract}

Key words: sectional methods, tree stem volume.

\section{RESUMEN}

Los métodos de Huber, Smalian y Newton para estimar el volumen de troncos y trozas de árbol por secciones, fueron evaluados teóricamente, aplicándolos a las geometrías de paraboloide, cono, y neiloide. El estudio sigue procedimientos de aproximación del cálculo para estimación de volumen de sólidos de revolución, como función del número de segmentos, y métodos de análisis de error de investigación en mediciones forestales. Se han determinado los errores en el uso de los métodos de Huber y Smalian. Adicionalmente, se probó algebraicamente que el error de Huber es exactamente la mitad del error de Smalian y de signo opuesto. Los resultados predicen que, para cualquier tronco modelado clásicamente, los errores porcentuales absolutos promedio de Huber y de Smalian deberían ser: menores que 13,5\% y $27 \%$, respectivamente, para cinco o más segmentos; menores que $7 \%$ y $14 \%$ para 10 o más segmentos; menores que 3,6 \% y 7,2 \%, para 20 o más segmentos; menores que 2,5\% y $5 \%$, para 30 o más segmentos. Este trabajo proporciona una cuantificación sobre la teoría clásica de estimación de volumen de troncos y trozas de árbol. Podría ser de utilidad para unificar dicha teoría y hacerla una referencia más compacta para enseñanza e investigación sobre mediciones forestales.

Palabras clave: métodos seccionales, volumen de tronco de árbol.

\section{INTRODUCTION}

Accurate determination of tree stem and log forms and volumes is a permanent question and represents main information in the forest measurement field; for instance, in forest inventory, tree growth and biomass estimation. The spectrum of methods for stem form and volume determination is extremely wide and the preferred methods are not the same in the different regions of the world or even of a country. Similarly, some of the methods in current use are different from those used in the past and new methods will be proposed in the future. It is beyond the scope of this work to make an extensive review on that subject. Inside that huge and diverse information, a standard or conven- tional knowledge is notorious, the named traditional, classical or old theory. Let us focus on it.

In the elementary forest measurement literature, tree stem shape, for tree stems of average circular cross-sections, is modeled by longitudinal sections using the solids of revolution: cylinder, paraboloid, cone, and neilod. Those will be called here classical geometries in agreement to Diéguez-Aranda et al. (2003).

Tree stem and log volumes depend on tree stem geometry. The most widely known sectional methods for volume estimation are: Smalian, Huber, and Newton methods. All three methods calculate volume based on cross-sectional areas; measured at the log ends (Smalian), at the midpoint (Huber), or at both ends and mid-point (Newton). 
Cross-sectional areas are assumed to be circular. In general, Huber's formula is more accurate even though it requires only one diameter to be measured. In particular, those methods are related to classical geometries. Then, they will be called here classical volume sectional methods. The three methods give exact results for cylinder and paraboloid. The Newton method gives exact results for all the classical geometries (Diéguez-Aranda et al. 2003). In the following, a review of known forest measurement literature about those methods is made.

Smalian and Huber methods are preferred in the field because they are easier to apply than the Newton method. It is generally known that the Smalian method is less accurate than the Huber method but it is more frequently used; particularly, when logs are stacked in piles where the mid-point diameter is not available for measurement. Historically, the opinions about the use of those two methods have been divided. Graves (1906) mentions the use of the Huber method in Europe and the Smalian method in USA but predicts the further adoption of the Huber method also in USA. Belyea (1931) and Bruce and Schumacher (1950) point that the Huber method is less used than the Smalian method in spite of its better accuracy. Philip (1994) affirms that log volumes are normally estimated by the Huber's formula.

Similarly, different opinions can be found about tree stem and log forms. For Chapman and Meyer (1949) tree stem form never approximates a cylinder and seldom a cone or neiloid. They affirm that the average log resembles the form of a truncated paraboloid. That supports the use of Smalian and Huber methods. For Bruce and Schumacher (1950) the most frequent log geometry is different from a perfect paraboloid. Then, they suggest the use of the Huber method. In words of Belyea (1931) a tree stem is more or less cone-like in form. He regards paraboloid and neiloid as deviations from the conic geometry. Bruce (1982) mentions the use of the truncated cone geometry in a region of USA to estimate volumes for all the logs of a tree stem in order to compensate for over and underestimations between upper and butt logs. Graves (1906) assures that most logs have a volume bigger than a truncated cone. For Chapman and Meyer (1949) log volume rarely lies between that of a frustum of paraboloid and that of a cylinder.

It is generally accepted that a truncated neiloid can approach the form of a tree stem at the lowest part. Neiloid geometry corresponds to the lower section up to an approximated height of $10 \%$ of tree total height (Van Laar and Akça 2007). Neiloid geometry affects butt log forms, which makes difficult their accurate volume estimation, particularly, for big diameters. Phillip (1994) assures that for a plantation-grown tree, $40 \mathrm{~cm}$ of diameter at breast height and $25 \mathrm{~m}$ tall, $80 \%$ of the tree stem volume is in the lowest $10 \mathrm{~m}$. He suggests the use of Huber's formula for that lowest part. Husch et al. (1982) say that for butt logs with excessive butt swell the Huber's method is even better than the Newton one. Graves (1906) assigns an error from 5 to $20 \%$, in using the Smalian method for butt logs, which depends on log length. Bruce (1982) developed a general method to estimate butt log volumes. An improved method supported on Bruce's work has been proposed by Patterson and Doruska (2004).

Unifying the whole information given formerly, a conclusion analog to that of Belyea (1931) can be obtained. It could be regarded that the geometry of most tree stem segments or logs should lie around a frustum of cone between the frustums of paraboloid and neiloid. Therefore, only those three geometries will be taken into account in this work.

The whole tree stem shape cannot be modeled conveniently by a single classical geometry. The average tree stem form is modeled as a truncated neiloid at the lowest part, a truncated paraboloid at the central section and a paraboloid or cone at the top (Husch et al. 1982, Avery and Burkhart 2002, Van Laar and Akça 2007). The main practical problem is that it is not possible to know exactly where one geometry ends and another begins (West 2004).

The classical theory of tree stems still represents a stimulating and solid reference in forest measurement teaching and research. Wood et al. (1990) used those geometries in the development of an important method of volume estimation in current use called the centroid method. Yavuz (1999) found that the centroid method, applied to logs of three species, is better than Newton, Huber and Smalian methods. However, using the water displacement technique, Figueiredo-Filho et al. (2000) have found that the Huber method performs better than the Newton, the Smalian, the centroid and other methods for a coniferous species. Inoue (2006) employed the classical geometries to derive a general relation between stem volume and surface area form-factors independent of position. Cruz de León (2010) obtained a general sectional volume equation for those geometries.

The classical theory will be a better established theory when its knowledge becomes unified. Perhaps, more quantitative analyses on those subjects, as the one proposed in this work, can help to get it.

The present work assumes that if a formal theoretical evaluation of the classical volume sectional methods, using methods from fundamental calculus and forest measurements, is made for paraboloid, cone and neiloid as function of the number of segments, then, the corresponding errors for those sectional methods can be computed. The main objective is to quantify the errors in the use of Smalian and Huber methods for each one of those geometries. Even when the Newton method is exact for the three geometries and Smalian and Huber methods are exact for paraboloid, they are included in the analysis to verify the correctness of the numerical treatment.

At the end of this work, the theoretical results obtained here are compared to those experimental ones obtained in a recent research by the xylometer technique on logs of teak trees (Akossou et al. 2013). 


\section{METHODS}

Approximation methods of calculus for volume estimation of solids of revolution. In agreement to the approximation methods of calculus for volume estimation, if a solid of revolution of length $H$ is divided in $n$ sections of length $H / n$, perpendicular to its axis of rotation, to each section corresponds a cylinder of the same length and approximate volume. The way to determine the individual cylinder volume defines a particular method. The total volume of the solid can be approached as the sum of the individual cylinder volumes. Conversely, to each cylinder corresponds a section of the solid and as the number of cylinders increases the approaching to volume improves (Stewart 2002). For instance, a simple method is defined choosing the cylinder diameter as that at a section end of the solid. Figure 1 shows that method for a paraboloid of total length $H$ sectioned in five parts of equal length $H / 5$ and five cylinders of that same length in a three dimensional Cartesian system. The cylinders cross sections are chosen as those at the right ends of the corresponding segments of paraboloid.

Implicitly, as it can be seen in figure 1, the form of a solid of revolution can be approximated by means of a sequence of defined cylinders and as the number of cylinders increases the approaching to the form improves.

Forest measurement methods for tree stem volume estimation. An analog process to that of the former section is known in the forest measurement literature to estimate the volume for a whole tree stem by longitudinal sections or segments. A given number of segments of the same length

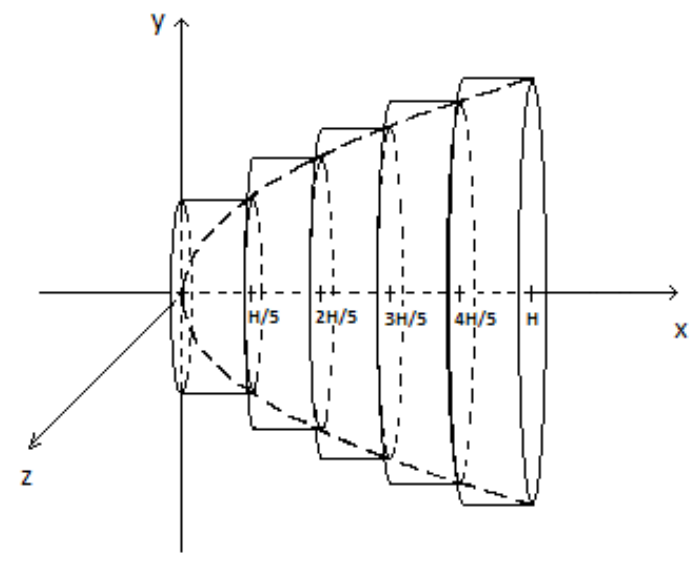

Figure 1. Volume of a paraboloid of length $H$, sectioned in five segments of individual length $H / 5$, approached by a sequence of five cylinders of the same length. The cylinders cross sections correspond to those at the right ends of the segments of paraboloid.

Volumen de un paraboloide de longitud $H$, seccionado en cinco segmentos de longitud individual $H / 5$, aproximado por una secuencia de cinco cilindros de la misma longitud. Las secciones transversales de los cilindros corresponden a los extremos derechos de los segmentos de paraboloide. are selected along the tree stem and their individual volumes are estimated using any classical sectional method, usually the Smalian or the Huber method (Bruce and Schumacher 1950).

Generating function for classical geometries. In forest measurement traditional literature, stem shape is modeled through the generating function,

$$
y^{2}=A_{m} x^{m}
$$

where $x$ and $y$ are the coordinates of a Cartesian plane, $A_{m}$ is a constant and $m=0,1,2$ and 3 . The solids of revolution related to equation [1] are cylinder, paraboloid, cone and neilod, respectively; formerly called classical geometries. The exact volumes for the classical geometries of total length $H$, defined here as $\mathrm{V}_{\mathrm{Exact,m}}$, are given by

$\mathrm{V}_{\text {Exact, } \mathrm{m}}=\int_{0}^{\mathrm{H}} \pi \mathrm{y}^{2} \mathrm{dx}=\pi \mathrm{A}_{\mathrm{m}} \frac{\mathrm{H}^{\mathrm{m}+1}}{\mathrm{~m}+1}$

Sectional methods. Sectional methods for tree stem volume measurements regard any section or segment, of length $L$, as a cylinder. In general, they can be defined in terms of a mean cross sectional area $\bar{S}$ for the segment such that its volume is given by $V=\bar{S} L$ (Avery and Burkhart 2002).

For a tree stem segment or log, of length $L$, end cross sectional areas, $S$ at the large end, $s$ at the small end and $\mathrm{S}_{1 / 2}$ at the middle, the mean cross sectional areas

$$
\begin{aligned}
& \bar{S}_{\text {Smalian }}=\left(\frac{S+S}{2}\right) \\
& \bar{S}_{\text {Huber }}=S_{1 / 2} \\
& \bar{S}_{\text {Newton }}=\left(\frac{S+4 S_{1 / 2}+S}{6}\right)
\end{aligned}
$$

define Smalian, Huber and Newton methods, respectively. Then, if a tree stem or log is modeled by a solid of revolution, those methods represent particular volume approximation methods of calculus.

General notation for the volumes. The following notation is defined here for the mathematical work. The individual volumes of tree stem segment for the different methods and geometries will be called $\mathrm{V}_{\mathrm{Method}, \mathrm{m}, \mathrm{n}, \mathrm{i} \text {. }}$; where method will refer to any of the Exact, Smalian, Huber and Newton methods, respectively. The remaining variables are: $m$, the power in equation [1] that refers to the geometry, $n$, the total number of segments, and $i$, the number of a particular segment. The total volume as function of the number of segments, given by the sum of the individual ones, is de- 
noted as $\bigvee_{M \text { ethod, } m, n \text {. }}$. Then,

$\mathrm{V}_{\text {Method }, \mathrm{m}, \mathrm{n}}=\sum_{\mathrm{i}=1}^{\mathrm{n}} \mathrm{V}_{\text {Method }, \mathrm{m}, \mathrm{n}, \mathrm{i}}$

Error analysis. In forest measurement literature, when different methods of volume estimation are compared for a set of logs, bias is usually estimated by the average percent error (APE) and accuracy by the average absolute percent error (AAPE) related to defined reference volumes (Figueiredo Filho et al. 2000, Patterson et al. 2007). In the present work, those parameters are used for error analyses taking as reference the exact volumes. Then, the APE corresponds to

$(A P E)_{\text {Method }, m, n}=\frac{1}{n} \sum_{i=1}^{n} \frac{\left(V_{\text {Method }, m, n, i}-V_{\text {Exact }, m, n, i}\right)}{V_{\text {Exact, } m, n, i}} \times 100$ [7]

APE gives an average measure of the percentage of over or underestimation in relation to exact volumes. Positive APE values mean overestimation and negative ones underestimation. Similarly, the average absolute percent error is given by

$(A A P E)_{\text {Method }, m, n}=\frac{1}{n} \sum_{i=1}^{n} \frac{V_{\text {Method }, m, n, i}-V_{\text {Exact }, m, n, i} \mid}{V_{E x a c t, m, n, i}} \times 100[8]$

AAPE is a measure of dispersion analog to the standard deviation. The standard deviation can also be used for the same type of error analysis (Plank and Cahill 1984). The results for the former parameters were obtained by means of Excel.

\section{RESULTS}

Derivation of the general equations for the individual volume of segment as function of the number of segments. If a classical geometry of length $H$ is sectioned in $n$ segments, of length $(H / n)$, the $X_{i}$ coordinates for the divisions of those intervals are $(i H / n)$; where, $i=1,2, \ldots, n$. In agreement to equation [1], their corresponding square radius are given by

$$
y_{i}^{2}=A_{m} x_{i}^{m}=A_{m}(i H / n)^{m}
$$

The exact volumes of segment as function of the total number of segments $V_{\text {Exact,m,n,i }}$ will be the reference values. They can be obtained using equation [2] for the difference between two whole figures whose bases are at $\mathrm{x}_{\mathrm{i}}=\mathrm{iH} / \mathrm{n}$ and $\mathrm{x}_{\mathrm{i}-1}=(\mathrm{i}-1) \mathrm{H} / \mathrm{n}$; resulting,

$V_{E x a c t, m, n, i}=\frac{\pi A_{m}}{(m+1)}\left[x_{i}^{m+1}-x_{i-1}^{m+1}\right]$ $=\frac{\pi A_{m} H^{m+1}}{m+1}\left[\left(\frac{i}{n}\right)^{m+1}-\left(\frac{i-1}{n}\right)^{m+1}\right]$

The normalized exact volume is defined here as

$$
V_{\text {Exact, } m, n, i}=\frac{V_{E x a c t, m, n, i}}{\pi A_{m} H^{m+1}}=\frac{1}{m+1}\left[\left(\frac{i}{n}\right)^{m+1}-\left(\frac{i-1}{n}\right)^{m+1}\right][
$$

For the Smalian method, the volume equation for an individual segment is

$$
\begin{aligned}
& V_{\text {Smalian, }, n, i}=\frac{1}{2}\left(\frac{H}{n}\right)\left[\pi y_{i}^{2}+\pi y_{i-1}^{2}\right] \\
& =\frac{\pi A_{m} H^{m+1}}{2 n}\left[\left(\frac{i}{n}\right)^{m}+\left(\frac{i-1}{n}\right)^{m}\right]
\end{aligned}
$$

Similarly, the corresponding normalized Smalian volume is defined as

$$
v_{\text {Smalian }, m, n, i}=\frac{1}{2 n}\left[\left(\frac{i}{n}\right)^{m}+\left(\frac{i-1}{n}\right)^{m}\right]
$$

For the Huber method, the radio is taken at the middle of the segment, then, the volume for the individual volume is given by

$$
\begin{aligned}
& V_{\text {Huber }, m, n, i}=\left(\frac{H}{n}\right)\left[\pi y_{[i+(i-1] / 2}^{2}\right] \\
& =\left(\frac{H}{n}\right)\left[\pi y_{(2 i-1) / 2}^{2}\right] \\
& =\frac{\pi A_{m} H^{m+1}}{n}\left[\left(\frac{2 i-1}{2 n}\right)^{m}\right]
\end{aligned}
$$

The normalized Huber volume is given by

$\mathrm{V}_{\text {Huber }, \mathrm{m}, \mathrm{n}, \mathrm{i}}=\frac{1}{\mathrm{n}}\left[\left(\frac{2 \mathrm{i}-1}{2 \mathrm{n}}\right)^{\mathrm{m}}\right]$

In general, the volume equation for the Newton method depends on the volumes given by Smalian and Huber methods (Cruz de León and Cruz de León 2006). The corresponding equation is

$\mathrm{V}_{\text {Newton, }, \mathrm{n}, \mathrm{i}}=\frac{2}{3} \mathrm{~V}_{\text {Huber }, \mathrm{m}, \mathrm{n}, \mathrm{i}}+\frac{1}{3} \mathrm{~V}_{\text {Smalian }, \mathrm{m}, \mathrm{n}, \mathrm{i}}$

or in normalized form 
$\mathrm{V}_{\text {Newton }, \mathrm{m}, \mathrm{n}, \mathrm{i}}=\frac{2}{3} \mathrm{~V}_{\text {Huber }, \mathrm{m}, \mathrm{n}, \mathrm{i}}+\frac{1}{3} \mathrm{~V}_{\text {Smalian }, \mathrm{m}, \mathrm{n}, \mathrm{i}}$

For $m=1$, the case of a paraboloid, equations [11-13] give the same result,

$\mathrm{V}_{\text {Exact }, m, n, i}=V_{\text {Smalian, } m, n, i}=V_{\text {Huber }, m, n, i}=V_{\text {Newton }, m, n, i}$

$=\left(\frac{2 i-1}{2 n^{2}}\right)$

which confirms that for a frustum of paraboloid any classical method gives the exact volume.

The normalized forms of equations [10-13] are nondimensional and were worked out using Excel for each geometry $m$, as function of $i$, and for $n=5,10,20,30$ and 100. All the individual normalized volumes of segments were computed and used to get the total normalized volumes and the APE and AAPE values.

Total normalized volumes as function of the number of segments. Table 1 shows the total normalized volumes for the different methods and geometries as function of the number of segments.

$A P E$ and $A A P E$ as function of the number of segments. The differences in total normalized volumes related to the exact values are significant and of practical interest only for the cases $n=5,10,20$ and 30. Table 2 shows the APE values obtained from the results for the normalized volumes of individual segments, corresponding to those $n$ values, for Smalian and Huber methods, and the studied geometries.

Particularly, for the problem of this work, it happens that AAPE $=|A P E|$. Then, it is enough to compute the APE values for each method and geometry. Their absolute values give the AAPE values. The AAPE values for table 2 are the same but the negative signs must be turned into positive.

\section{DISCUSSION AND CONCLUSIONS}

The numerical results of this work, shown in tables 1 and 2, confirm what is known about the standard methods. The Newton method is exact for paraboloid, cone and nei- loid. Smalian and Huber methods are exact for paraboloid. Table 2 shows that for cone and neiloid Smalian overestimates and Huber underestimates volume in agreement to Husch et al. (1982). However, those deviations are quantified here as a function of the number of segments.

Belyea (1931) affirms that for geometries going from paraboloid to neiloid, except for paraboloid itself, the error by Huber's formula is approximately half of Smalian's formula and is mathematically opposite in value. Chapman and Meyer (1949) state that the error is just a half. Equivalently, Husch et al. (1982) assure that the Smalian's error is twice the Huber's error and opposite in sign. Philip (1994) proved mathematically that the Huber's error is exactly a half of the Smalian's one and of opposite sign for a cone. The numerical APE results of table 2 show that, for a neiloid, the error in volume estimation using the $\mathrm{Hu}-$ ber method is closely to a half of the Smalian error and of opposite sign in agreement to the assertions of Belyea (1931); though, for a cone, the Huber's error is exactly a half of Smalian's error and of opposite sign in agreement to Phillip (1994).

The question whether the error in volume estimation using the Huber method is closely or exactly a half of the Smalian error and of opposite sign, as cited references suggest, arises. Due to their numerical nature, the previous results of this work give an apparent ambiguous answer. Husch et al. (1982) provide only a textual proof of their assumption as follows: it can be shown that subtracting

Table 2. APE values (\%) for Smalian and Huber methods applied to classical geometries as function of the number of segments $n$.

Valores del APE (\%) para los métodos de Smalian y Huber aplicados a las geometrías clásicas como función del número de segmentos $n$.

\begin{tabular}{ccccccc}
\hline & \multicolumn{2}{c}{ Paraboloid } & \multicolumn{2}{c}{ Cone } & \multicolumn{2}{c}{ Neiloid } \\
\cline { 2 - 7 } & Smalian & Huber & Smalian & Huber & Smalian & Huber \\
\hline 5 & 0 & 0 & 12.4 & -6.2 & 26.8 & -13.4 \\
10 & 0 & 0 & 6.4 & -3.2 & 13.9 & -6.9 \\
20 & 0 & 0 & 3.2 & -1.6 & 7.1 & -3.5 \\
30 & 0 & 0 & 2.2 & -1.1 & 4.7 & -2.4 \\
\hline
\end{tabular}

Table 1. Total normalized volumes of paraboloid, cone and neiloid, for the classical sectional methods as function of the number of segments $n$.

Volúmenes totales normalizados de paraboloide, cono y neiloide, para los métodos seccionales clásicos como función del número de segmentos $n$.

\begin{tabular}{rccccccccc}
\hline & \multicolumn{3}{c}{ Paraboloid } & \multicolumn{3}{c}{ Cone } & \multicolumn{3}{c}{ Neiloid } \\
\cline { 2 - 10 } & Newton & Smalian & Huber & Newton & Smalian & Huber & Newton & Smalian & Huber \\
\hline 5 & 0.5 & 0.5 & 0.5 & 0.33333 & 0.34000 & 0.33000 & 0.25000 & 0.26000 & 0.24500 \\
10 & 0.5 & 0.5 & 0.5 & 0.33333 & 0.33500 & 0.33250 & 0.25000 & 0.25250 & 0.24875 \\
20 & 0.5 & 0.5 & 0.5 & 0.33333 & 0.33375 & 0.33313 & 0.25000 & 0.25063 & 0.24969 \\
30 & 0.5 & 0.5 & 0.5 & 0.33333 & 0.33352 & 0.33324 & 0.25000 & 0.25027 & 0.24986 \\
100 & 0.5 & 0.5 & 0.5 & 0.33333 & 0.33335 & 0.33333 & 0.25000 & 0.25003 & 0.24999 \\
\hline
\end{tabular}


Newton's formula, first from Smalian's formula and then from Huber's formula, the error incurred by Smalian's formula is twice that incurred by Huber's formula and opposite in sign. In the present work, before the reference of Husch et al. (1982) was available, the same answer had been algebraically proved independently following the Chapman and Meyer assumption (1949) and the equivalent Newton formula given by Cruz de León and Cruz de León (2006), from which equation [13a] was derived. That formal proof is added in the appendix of this work.

In studies of tree stem volume by sections the question of segment length needs to be addressed. West (2004) suggests section lengths of $0.5-1 \mathrm{~m}$ for large trees and shorter lengths for small trees. Van Laar and Akça (2007) suggest segments of $1 \mathrm{~m}$ in length for trees below $12 \mathrm{~m}$, and $2 \mathrm{~m}$ for trees larger than $12 \mathrm{~m}$. Both proposals can be unified considering an interval of $0.5-2 \mathrm{~m}$ for the length of the tree stem segments. Assuming intervals of the same length the results shown in table 2 of this work, as function of the number of segments, would correspond to tree stem total height intervals 2.5-10 m, 5-20 m, 10-40 m and 15-60 m.

From table 2 and from the fact that the magnitude of the Huber's error is exactly a half of the magnitude of the Smalian's error, upper-limits for the AAPE can be deduced, independently on the tree stem geometry. The AAPE in using Huber and Smalian methods to estimate tree stem volumes would be less than $13.5 \%$ and $27 \%$ from the exact values, respectively, if the number of segments is equal to or larger than 5 ; less than $7 \%$ and $14 \%$ for a number of segments equal to or larger than 10; less than $3.6 \%$ and $7.2 \%$ for a number of segments equal to or larger than 20 ; and less than $2.5 \%$ and $5 \%$ if the number of segments is equal to or larger than 30. The Huber's error lies between $2.5 \%$ and $13.5 \%$. The Smalian's error is between $5 \%$ and $27 \%$, close to the $5 \%$ to $20 \%$ pointed by Graves (1906) for butt logs.

In an experimental study by means of the xylometer technique on logs of teak trees to study the errors in tree stem volume estimation, as function of log length, for tree stems of nearly $15 \mathrm{~m}$ of total height, Akossou et al. (2013) found that both Huber and Smalian methods overestimate tree stem volumes. For logs $0.5 \mathrm{~m}$ long, the maximum errors are $3 \%$ for the Huber method and $4 \%$ for the Smalian method. For logs $1 \mathrm{~m}$ long, the same errors are $8 \%$ and $9 \%$, respectively. For logs $3 \mathrm{~m}$ long the corresponding errors are $10 \%$ and $24 \%$. The maximum Huber's error lies between $3 \%$ and $10 \%$. The maximum error for the Smalian method is between $4 \%$ and $24 \%$.

In the study discussed above, $15 \mathrm{~m}$ of total height and logs of $0.5 \mathrm{~m}, 1 \mathrm{~m}$ and $3 \mathrm{~m}$ would correspond to numbers of segments $n=30,15$ and 5, respectively, in this work. Although it has not been computed the case for $n=15$, table 2 shows that for $n=30$ the maximum Huber error is $2.5 \%$ and the maximum Smalian error is $5 \%$. For $n=5$, those errors are $13.5 \%$ and $27 \%$, respectively. In theory, the Huber method underestimates volume; though, should attention be given only to the magnitude of the maximum errors, the experimental data are close to the theoretical predicted values of the present work.

The main objective defined for this work has been obtained. The errors by volume estimation of Huber and Smalian methods for the classical geometries paraboloid, cone and neiloid, as function of the number of segments, have been determined. Common qualitative knowledge on the classical theory of tree stem measurements has been quantitatively verified. Theoretical results are in agreement to experimental data. Finally, it has been explicitly proved that the error in using the Huber method for volume estimation is exactly a half of the error corresponding to the Smalian method and opposite in sign for the classical geometries.

\section{REFERENCES}

Akossou AYJ, S Arzouma, EY Attakpa, NH Fonton, K Kokou. 2013. Scaling of teak (Tectona grandis) logs by the xylometer technique: accuracy of volume equations and influence of the log length. Diversity 5: 99-113.

Avery TE, HE Burkhart. 2002. Forest Measurements. New York, USA. Mc Graw Hill. 456 p.

Belyea HC. 1931. Forest Measurement. New York, USA. John Wiley. 319 p.

Bruce D. 1982. Butt Log Volume Estimators. Forest Science 28(3): 489-503.

Bruce D, FX Schumacher. 1950. Forest Mensuration. New York, USA. McGraw-Hill. 483 p.

Chapman HH, WH Meyer. 1949. Forest Mensuration. New York, USA. McGraw-Hill. 522 p.

Cruz de León G, J Cruz de León. 2006. The segmental conic model for forest measurements. Madera y Bosques 12(2): 91-96.

Cruz de León G. 2010. A general sectional volume equation for classical geometries of tree stem. Madera y Bosques 16(2): 89-94.

Diéguez-Aranda U, M Barrio-Anta, F Castedo-Dorado, AD Ruíz-González, MF Álvarez-Taboada, JG Álvarez-González, A Rojo-Albareca. 2003. Dendrometría. Madrid, España. Mundi-Prensa. 327 p.

Figueiredo-Filho A, S Amaral-Machado, MR Araújo-Carneiro. 2000. Testing accuracy of log volume calculation procedures against water displacement techniques (xylometer). Canadian Journal of Forest Research 30: 990-997.

Graves HS. 1906. Forest Mensuration. New York, USA. John Wiley and Sons. 458 p.

Husch B, ChI Miller, TW Beers. 1982. Forest mensuration. New York, USA. John Wiley and Sons. 402 p.

Inoue A. 2006. A model for the relationship between form-factors for stem volume and those for stem surface area in coniferous species. Journal of Forest Research 11: 289-294.

Patterson DW, PF Doruska. 2004. A new and improved modification to Smalian's equation for butt logs. Forest Products Journal 54: 69-72.

Patterson DW, PF Doruska, J Hartley, M Hurd. 2007. Validating the Patterson and Doruska equation for estimating the volume of hardwood butt logs. Forest Products Journal 57: 67-70.

Philip MS. 1994. Measuring Trees and Forests. London, UK. 
CABI Publishing. 310 p.

Plank ME, JM Cahill. 1984. Estimating Cubic Volume of Small

Diameter Tree-Length Logs From Ponderosa and Lodgepole Pine. United States Department of Agriculture. Forest Service. Research. Note PNW-417.

Stewart J. 2002. Cálculo Trascendentes Tempranas. México. Thompson Learning. 1151 p.

van Laar A, A Akça. 2007. Forest Mensuration. Dordrecht, The Netherlands. Springer. 383 p.
West PW. 2004. Tree and Forest Measurement. Berlín, Germany. Springer. $167 \mathrm{p}$.

Wood GB, HV Wiant, RJ Loy, JA Miles. 1990. Centroid Sampling: A variant of importance sampling for estimating the volume of sample trees of radiate pine. Forest Ecology and Management 36:233-243.

Yavuz H. 1999. Comparison of the centroid method and four standard formulas for estimating log volumes. Turkish Journal of Agriculture and Forestry 23:597-602.

Recibido: 13.05 .13

Aceptado: 03.10.13

\section{APPENDIX}

Proof about that the error of the Huber method is exactly a half of the error of the Smalian method and opposite in sign. Ordering terms in the traditional Newton formula leads to the general relation among Newton, Huber and Smalian volumes

$\mathrm{V}_{\text {Newton }}=\frac{2}{3} \mathrm{~V}_{\text {Huber }}+\frac{1}{3} \mathrm{~V}_{\text {Smalian }}$

(Cruz de León and Cruz de León 2006) from which equation [13a] of this work was derived. The former equation also can be written as

$\mathrm{V}_{\text {Newton }}=\mathrm{V}_{\text {Huber }}+\frac{1}{3}\left(\mathrm{~V}_{\text {Smalian }}-\mathrm{V}_{\text {Huber }}\right)$

and

$\left.\mathrm{V}_{\text {Newton }}=\mathrm{V}_{\text {Smalian }}+\frac{2}{3} \mathrm{~V}_{\text {Huber }}-\mathrm{V}_{\text {Smalian }}\right)$

Those equations lead to the following corresponding equations

$\mathrm{V}_{\text {Huber }}=\mathrm{V}_{\text {Newton }}-\frac{1}{3}\left(\mathrm{~V}_{\text {Smalian }}-\mathrm{V}_{\text {Huber }}\right)$

and

$\mathrm{V}_{\text {Smalian }}=\mathrm{V}_{\text {Newton }}-\frac{2}{3}\left(\mathrm{~V}_{\text {Huber }}-\mathrm{V}_{\text {Smalian }}\right)$

As the Newton volume corresponds to the exact volume for all the classical geometries, the Huber's error to estimate volume, called here $E_{\text {Huber }}$ can be defined as

$$
E_{\text {Huber }}=-\frac{1}{3}\left(V_{\text {Smalian }}-V_{\text {Huber }}\right)
$$

and the Smalian's error, called here $E_{\text {Smalian }}$, as

$$
E_{\text {Smalian }}=-\frac{2}{3}\left(V_{\text {Huber }}-V_{\text {Smalian }}\right)
$$

It can be seen that

$$
E_{\text {Smalian }}=-2\left[-\frac{1}{3}\left(V_{\text {Smalian }}-V_{\text {Huber }}\right)\right]
$$

and using the former definition of the Huber's error it happens that

$$
\mathrm{E}_{\text {Smalian }}=-2 \mathrm{E}_{\text {Huber }}
$$

then,

$$
E_{\text {Huber }}=-\frac{1}{2} E_{\text {Smalian }}
$$

which means that, for any classical geometry, the Huber's error is exactly a half of the Smalian's error and of opposite sign as it was affirmed in the conclusions of this work. 
